\title{
Correction to: An Overview of Mesenchymal Stem Cell-based Therapy Mediated by Noncoding RNAs in the Treatment of Neurodegenerative Diseases
}

\author{
Yifei Luo $^{1} \cdot$ Wei Qiu ${ }^{1}$ Buling $\mathrm{Wu}^{1,2} \cdot$ Fuchun Fang $^{1}$ (D)
}

Published online: 1 October 2021

๑) Springer Science+Business Media, LLC, part of Springer Nature 2021

\section{Correction to: Stem Cell Reviews and Reports}

$$
\text { https://doi.org/10.1007/s12015-021-10206-X }
$$

The original version of this article unfortunately contained a mistake. The author name Yifei Luo was incorrectly written as Yifen Luo.

The original article has been corrected.

Publisher's Note Springer Nature remains neutral with regard to jurisdictional claims in published maps and institutional affiliations.

The original article can be found online at https://doi.org/10.1007/ s12015-021-10206-x.

Fuchun Fang

fangfuchun520@163.com

1 Department of Stomatology, Nanfang Hospital, Southern Medical University, 1838 Guangzhou Avenue North, Guangzhou 510515, People's Republic of China

2 Shenzhen Stomatology Hospital (Pingshan), Southern Medical University, 143 Dongzong Road, Pingshan District, Shenzhen 518118, People's Republic of China 